Natural Hazards and Earth System Sciences, 5, 583-592, 2005

SRef-ID: 1684-9981/nhess/2005-5-583

European Geosciences Union

(C) 2005 Author(s). This work is licensed

under a Creative Commons License.

\title{
Monitoring soil wetness variations by means of satellite passive microwave observations: the HYDROPTIMET study cases
}

\author{
T. Lacava ${ }^{1}$, M. Greco ${ }^{2,3}$, E. V. Di Leo ${ }^{1}$, G. Martino ${ }^{2}$, N. Pergola ${ }^{1}$, F. Sannazzaro ${ }^{2}$, and V. Tramutoli ${ }^{1,2,3}$ \\ ${ }^{1}$ Istituto di Metodologie per l'Analisi Ambientale - CNR, Tito Scalo (Potenza), Italy \\ ${ }^{2}$ Dip. di Ingegneria e Fisica dell'Ambiente, Università della Basilicata, Potenza, Italy \\ ${ }^{3}$ CIMA - Università della Basilicata, Università di Genova, Italy
}

Received: 28 February 2005 - Revised: 21 April 2005 - Accepted: 3 May 2005 - Published: 1 August 2005

Part of Special Issue "HYDROPTIMET"

\begin{abstract}
Soil moisture is an important component of the hydrological cycle. In the framework of modern flood warning systems, the knowledge of soil moisture is crucial, due to the influence on the soil response in terms of infiltrationrunoff. Precipitation-runoff processes, in fact, are related to catchment's hydrological conditions before the precipitation. Thus, an estimation of these conditions is of significant importance to improve the reliability of flood warning systems. Combining such information with other weatherrelated satellite products (i.e. rain rate estimation) might represent a useful exercise in order to improve our capability to handle (and possibly mitigate or prevent) hydro-geological hazards.

Remote sensing, in the last few years, has supported several techniques for soil moisture/wetness monitoring. Most of the satellite-based techniques use microwave data, thanks to the all-weather and all-time capability of these data, as well as to their high sensitivity to water content in the soil. On the other hand, microwave data are unfortunately highly affected by the presence of surface roughness or vegetation coverage within the instantaneous satellite field of view (IFOV). Those problems, consequently, strongly limit the efficiency and the reliability of traditional satellite techniques.

Recently, using data coming from AMSU (Advanced Microwave Sounding Unit), flying aboard NOAA (National Oceanic and Atmospheric Administration) satellites, a new methodology for soil wetness estimation has been proposed. The proposed index, called Soil Wetness Variation Index $(S W V I)$, developed by a multi-temporal analysis of AMSU records, seems able to reduce the problems related to vegetation and/or roughness effects. Such an approach has been tested, with promising results, on the analysis of some flooding events which occurred in Europe in the past.
\end{abstract}

Correspondence to: N. Pergola

(pergola@imaa.cnr.it)
In this study, results achieved for the HYDROPTIMET test cases will be analysed and discussed in detail. This analysis allows us to evaluate the reliability and the efficiency of the proposed technique in identifying different amounts of soil wetness variations in different observational conditions. In particular, the proposed indicator was able to document the actual effects of meteorological events, in terms of space-time evolution of soil wetness changes, for all the analysed HYDROPTIMET test cases. Moreover, in some circumstances, the $S W V I$ was able to identify the presence of a sort of "early" signal in terms of soil wetness variations, which may be regarded as a timely indication of an anomalous value of soil water content. This evidence suggests the opportunity to use such an index in the pre-operational phases of the modern flood warning systems, in order to improve their forecast capabilities and their reliability.

\section{Introduction}

In the last few years, remotely sensed observations have been largely used in the framework of hydro-meteorological risk mitigation. Satellite data, in fact, have increasingly become a useful tool for providing hydrological information, including the quantification of the main physical characteristics of the catchment, such as topography and land use (Pultz et al., 1991 and 1997), and of catchment variables, like soil moisture or snow cover (Scofield and Achtuni, 1996; Ferraro et al., 1996).

In particular, since the soil response is affected by its status of saturation, the knowledge of soil moisture is very important concerning flood forecast and prevention (Entekhabi et al., 1994, Wigneron et al., 1998; Walker and Houser, 2004). Combining information about soil water content with other weather-related satellite products (i.e. rain rate estimation), 
might represent a useful exercise in order to improve our capability to handle (and possibly mitigate or prevent) hydrogeological hazards. Moreover, besides the warning phase, soil wetness mapping/monitoring is important during the crisis and post-crisis phases as well, allowing a possible timely monitoring of flooded areas and giving the opportunity to take useful damage mitigation decisions (CEOS, 2003). Besides, soil moisture plays a key role in the hydrological cycle, having a direct influence in many of the processes which occur on the Earth's surface (Entekhabi et al., 1994).

Many satellite techniques have already been proposed to remotely map flooded areas and to monitor hydrogeophysical parameters like soil moisture. The main advantage of satellite remote sensing is the capability of systematically covering large areas with spatially continuous records.

Traditional satellite techniques for soil moisture monitoring exploit the microwave data advantages, since at these frequencies: i) electro-magnetic radiation leaving the Earth's surface is practically not affected by clouds (in the absence of rain), allowing an "all-weather" capability; ii) the microwave signal is available both during the day and night assuring an "all-time" capability of observing the Earth's surface conditions; iii) thanks to the large contrast between dielectric properties of water and dry soil, microwaves are highly sensitive to the water content in the soil (Eagleman and Lin, 1976; Jackson et al., 1981).

Notwithstanding the above mentioned importance to have frequently updated and reliable information about soil moisture variations and although a number of satellite techniques have been proposed to this aim, up to now satellite products are not yet routinely used in hydrological models.

The main reason is because, unfortunately, the estimate of soil moisture by means of microwave radiances is strongly affected by surface roughness and vegetation cover, whose contributions may perturb the measured signal, often masking the effects induced by soil moisture changes (Choudhury et al., 1979; Wang et al., 1983; Jackson and Schmugge, 1989; Prigent et al., 1997; Schmugge et al., 2002).

In specific literature there are many studies providing suggestions to reduce or minimize these effects, often combining data acquired in multi-configuration system (Ahmed, 1995; Paloscia et al., 1993; Njoku and Entekhabi, 1996; Njouku and Li, 1999; Ruf and Zhang, 2001; Kim and Barros, 2002), or using a large amount of ancillary data (Ahmed, 1995; Choudhury and Golus, 1988; Wang, 1985; Jackson and Schmugge, 1991; Jackson, 1993). However, ancillary data are often unavailable and the use of data acquired in different configurations is not always possible and it is frequently difficult to achieve (Wigneron et al., 2003), so that the reduction of the above-mentioned roughness and vegetation effects is only partly achievable.

A new technique for soil wetness monitoring has recently been proposed (Lacava et al., 2005). It is based on a multitemporal analysis of data acquired from AMSU (Advanced Microwave Sensor Unit) sensor. AMSU is the microwave radiometer aboard NOAA (National and Oceanic Atmospheric Administration) polar satellites, operational since 1998. Cur- rently, it is flying aboard NOAA-15, NOAA-16 and NOAA17 platforms, and it will also be aboard NOAA-18, which is scheduled to be launched in May 2005 (NOAA-OSD, http://www.oso.noaa.gov/poesstatus/index.asp). The particular configuration of NOAA satellites constellation, with at least two satellites orbiting 6 hours apart, allow us to acquire at least four images per day. This circumstance gives us the opportunity to potentially have frequent information about the space-time variability of soil moisture (at a regional scale), crucial information in order to provide a support in flooding risk management.

The main objective of the HYDROPTIMET project, funded within the Interreg IIIB - Medocc program (http: //hydroptimet.medocc.org), is the better comprehension of the hydro-meteorological phenomena as well as the optimization of the instruments for their forecast, prevention and mitigation, also by integrating different information. In this context, the possibility to assimilate reliable and frequently updated satellite products in flood forecast systems, might represent an unique opportunity.

The new approach proposed, which seems able to overcome the above mentioned problems related to soil roughness and vegetation, has been applied with good results for the analysis of some flooding events which affected European countries in the past (Lacava, 2004; Lacava et al., 2004 and 2005). In this study, the results obtained by the analysis of the study cases selected within the INTERREG IIIB Medocc "HYDROPTIMET" project will be presented and discussed in a possible operational scenario.

\section{The Advanced Microwave Sounding Unit (AMSU)}

Best soil moisture/wetness information is achievable with microwave radiometer acquiring data at $\mathrm{L}$ band (Schmugge et al., 1980; Jackson and Schmugge 1989; Entekhabi et al., 1994; Galantowicz et al., 1999; Njoku and Li, 1999.). At these frequencies, in fact, vegetation is almost transparent; the roughness effects are negligible and the soil water information is more reliable since it comes out from deeper soils (Schmugge, 1998).

To date, there is no spaceborne sensor measuring the microwave emission of the soil surface at this frequency (Schmugge et al., 2002), although several new programs are scheduled: the European Space Agency passive L-band Soil Moisture and Ocean Salinity (ESA-SMOS) mission (2007 launch) and the U.S. National Aeronautics and Space Administration active/passive L-band HYDROSpheric states (NASA-HYDROS) mission (2009 launch) are two examples. Therefore, there is an urgent need to adapt other microwave sensors to this application (Jackson 1997, Paloscia et al., 2001; Jackson et al., 2002; Walker and Houser, 2004). Working in the framework of hydro-geological risk mitigation, where the critical problem is to follow the rapid variations of superficial conditions, the choice will be addressed towards those satellite sensors which ensure high revisit time (Schmugge et al., 2002). 
AMSU satisfies this requirement, besides its spatial resolution is suitable for hydrometeorology and hydroclimatology studies; moreover, it can guarantee a sort of continuity of data dissemination since AMSU-A is already operational aboard EOS-AQUA and it is planned to be carried on the next MetOp (Meteorological Operational Satellite) ESA mission as well.

The Advanced Microwave Sounding Unit is a new generation microwave sensor that consists of two modules: the AMSU-A module includes 15 channels in the $23-89 \mathrm{GHz}$ range with a spatial resolution of $48 \mathrm{~km}$ at Nadir, it was primarily designed for temperature soundings of the atmosphere from the surface to about 2 millibar pressure altitude (48 km) (Goodrum et al., 1997); the AMSU-B module contains one channel centred at $89 \mathrm{GHz}$ and four channels around the $183.21 \mathrm{GHz}$ water vapour line; it was designed for deriving atmospheric moisture profiles with a spatial resolution of $16 \mathrm{~km}$. AMSU also includes window channels at 23.8, 31.4, 50.3 and $89.0 \mathrm{GHz}$ (channels 1, 2, 3, 15 and 16) to monitor surface features, such as soil moisture.

Many of the algorithms developed for AMSU derive from past experiences acquired with SSM/I (Special Sensor Microwave Imager) (Ferraro et al., 1986 and 1996; Teng et al., 1993; Scofield and Achutuni, 1996; Lakshmi et al., 1997; Prigent et al., 1997; Basist et al., 1998 and 2001; William et al., 2000), which is the radiometer aboard DMSP (Defence Meteorological Satellite Program) satellites (Hollinger et., 1997).

In particular, the relation between surface emissivity and soil water content has been well studied. Primarily, adding water into a soil produces a decrease in the surface emissivity (Lakshmi et al., 1997), precisely, for the same soil water content, the emissivity is higher for higher frequencies (Prigent et al., 1997). Specifically, the slope between the low and high frequencies directly responds to the amount of the radiating surface that is liquid water (Basist et al., 1998, and 2001; William et al., 2000).

In the presence of water, in fact, any surface could be viewed as the combination between dry soil and water, being $f$ the fractional amount of water covered area within an AMSU pixel. Then the microwave emissivity of wet soil in each pixel can be calculated as (Basist et al., 1998; Songyan et al., 2000):

$\varepsilon_{w s}=(1-f) * \varepsilon_{d s}+\varepsilon_{w} f=\varepsilon_{d s}-f\left(\varepsilon_{d s}-\varepsilon_{w}\right)$

where $\varepsilon_{w s}, \varepsilon_{d s}$ and $\varepsilon_{w}$ are the emissivity of wet soil, dry soil and water. As the fractional amount of wet land increases, the emissivity decreases and its difference between low and high frequencies increases (Basist et al., 1998).

In this sense, a combination of two properly selected window AMSU channels may give us useful information about superficial emissivity variations (Songyan et al., 2000; Grody, 2002 ${ }^{1}$ ). The problem will be the measuring of the amount of this variation which is actually related to different

\footnotetext{
${ }^{1}$ Grody, N. C.: An AMSU Soil Wetness Index, private communication, 2002.
}

soil water content, discriminating it from the contributions due to vegetation cover and/or superficial roughness effects.

\section{The Soil Wetness Variation Index (SWVI)}

In order to try to overcome (or reduce) the problems related to vegetation and/or roughness effects, a new technique has already been suggested (Lacava et al., 2005). It is based on a general data analysis strategy, the RAT (Robust AVHRR Techniques - Tramutoli, 1998) approach. This is an automatic change-detection scheme that identifies signal anomalies in the space-time domain as deviations from a normal state that has been preliminarily identified (and usually given in terms of time average and standard deviation) on the basis of satellite observations collected during several years, under similar observational conditions for each image pixel.

When applied to soil wetness monitoring, RAT allows us to overcome all the above mentioned site effects, not only the ones due to surface roughness or vegetation cover, but also the ones due to the presence of permanent water bodies within the instantaneous field of view (IFOV) of the sensor. The same site observed under the same observational conditions (same month of year, same time of day), in fact, is expected to have the same roughness and quite similar vegetation cover, so that the possible emissivity variations observed can mainly be attributed to moisture variations in the soil (Lacava et al., 2005).

The innovative Soil Wetness Variation Index (SWVI) has been defined as follows:

$S W V I(x, y, t)=\frac{S W I(x, y, t)-\mu_{S W I}(x, y)}{\sigma_{S W I}(x, y)}$

where: $S W I(x, y, t)$ is a hypothetical soil wetness index defined as the difference $\left(S W I=T_{89 \mathrm{GHz}}-T_{23 \mathrm{GHz}}\right)$ between the radiance (expressed in Brightness Temperature) measured in AMSU channels 15 (at $89 \mathrm{GHz}$ ) and 1 (at $23 \mathrm{GHz}$ ), respectively. As mentioned above, $S W I$ may provide useful information about surface emissivity variations, but it is unable to discriminate the amount of these variations which are actually related to different soil water content from the ones which are mainly due to vegetation and/or roughness effects. $\mu_{S W I}(x, y)$ is the time average of $S W I$, and $\sigma_{S W I}(x, y)$ is its standard deviation describing its natural fluctuations, both computed on a selected, multi-annual AMSU imagery data-set composed only from AMSU data, collected during the same month of the year and acquired at around the same hour of the day. Then the $S W V I(x, y, t)$ gives, for each pixel $(x, y)$, the actual $S W I$ excess compared to its unperturbed conditions $\left(S W I(x, y)-\mu_{S W I}(x, y)\right)$, for place $(x, y)$ and time $t$ of observation, weighed by the normal variability, $\sigma_{S W I}(x, y)$ of $S W I(x, y, t)$, historically observed for that place $(x, y)$ under similar observational conditions. The site effects, mainly due to surface roughness or vegetation cover as well as to the presence of permanent water bodies within the instantaneous field of view (IFOV), are strongly reduced: the $S W V I(x, y, t)$ index, in fact, is solely sensitive 


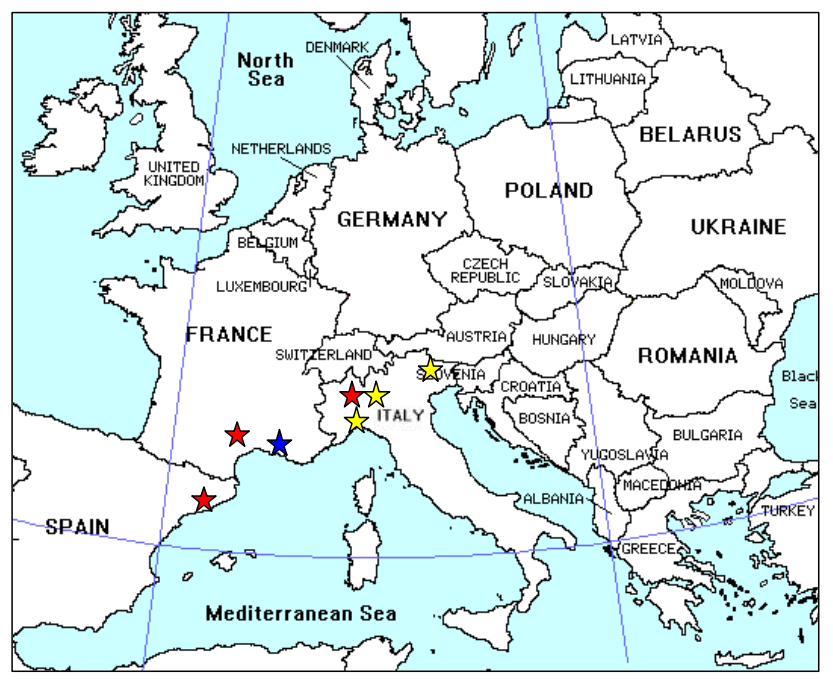

Fig. 1. HYDROPTIMET study case locations. Red stars identify the main areas affected by the flooding event occurred in June 2000. With the blue star the area affected by the French HYDROPTIMET test case, which occurred in September 2002, is flagged whereas the yellow stars localize the Piedmont areas of November 2002 floods.

to $S W I$ variations (for each place mainly depending on soil moisture) and not to its absolute value (strongly depending instead also on surface roughness and vegetation cover). We expect, then, that higher values of $S W V I(x, y, t)$ will be associated to a relative increase of soil wetness at each specific location.

Moreover, such an approach takes into account all the possible noise effects, including the ones related to navigation and co-location processes or to the system configuration (e.g. different viewing angles, different path lengths, etc.). It is to be expected that all these problems will produce an increase of $\sigma_{S W I}(x, y)$, and a consequent decrease of $S W V I(x, y, t)$ values which could give us only a much-more selective identification of over-threshold events (Tramutoli, 1998).

\section{The HYDROPTIMET study cases}

The proposed SWVI has recently been tested during several flooding events occurred in Europe in the last few years. In particular, the proposed indicator has been validated within the activity of the HYDROPTIMET project, in the framework of the INTERREG IIIB Medocc program.

Within the HYDROPTIMET project, some different flooding events have been selected as study cases; in Fig. 1 the locations of the selected events are reported. They differ for the temporal length, or for the spatial extension of the area involved as well as for the impact and the damages caused. In the following , the three HYDROPTIMET flooding events will be briefly described (more details are available on the web-site of the project, as well as in other papers of this special issue).
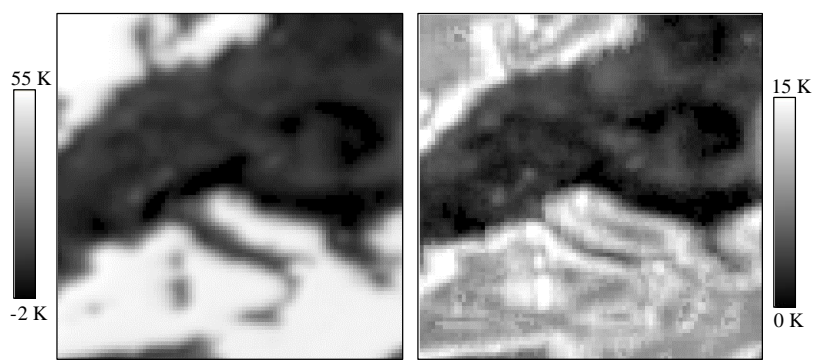

Fig. 2. Reference fields computed for the dataset including all the imagery acquired in September (from 1998 until 2003) between 5:00 and 7:00 GMT: the average (on the left) and the standard deviation (on the right) derived for the signal $S W I$. Both the images are plotted in grey tones (brighter tones correspond to pixel with higher brightness temperatures). Colour bars indicate the whole range of fluctuation for each field.

- 9-10 June 2000, Catalonia (Spain). A "flash flood" affected, on 9th and 10th of June 2000, the Spanish region of Catalonia, in particular Barcelona and the neighboring areas. In some localities $224 \mathrm{~mm}$ of rain fell in less than $6 \mathrm{~h}$, causing the Llobregat river and its tributaries to overflow: 5 people died and hundreds were evacuated. Afterwards the precipitation moved towards the south of France on 10th and 11th of June. In particular, the areas which were more involved were the Rhone Alps, the Loire Valley's Coise River, Toulouse and the whole Ariege region. The flood event caused 1 victim and hundreds of evacuees. On 11th, 12th and 13th of June the rains reached the North-East of Italy, especially the Piedmont region where about $220 \mathrm{~mm}$ of rain fell, causing enormous damages to the infrastructures and to the road network.

- 8-9 Semptember 2002, Cévennes (France). The flood was produced by torrential rains between 8 th and 9th of September. In fact, more than $650 \mathrm{~mm}$ of rain fell in $24 \mathrm{~h}$ over the southern part of France. The banks of the Rhone and some of its tributaries were overcome causing 26 fatalities and thousands of evacuees. The interested cities were Nimes, Orange, Avignon and the neighboring villages.

- 14-18 and 23-27 November 2002, Piedmont (Italy). It was a "double" event because it occurred in two subsequent phases: the first one between 14th and 18th of November and the second one from 23rd to 27th of November (stressing the already catastrophic effects produced by the first event). Heavy rains caused the level of rivers, lakes and torrents to grow which overcame their banks leading to the evacuation of thousands of people and enormous damages. During the first meteorological phase, the most hit region was the Lombardy, where about $300 \mathrm{~mm}$ of rain fallen in two days. In the second phase the precipitation affected many of the regions located in northern Italy. 

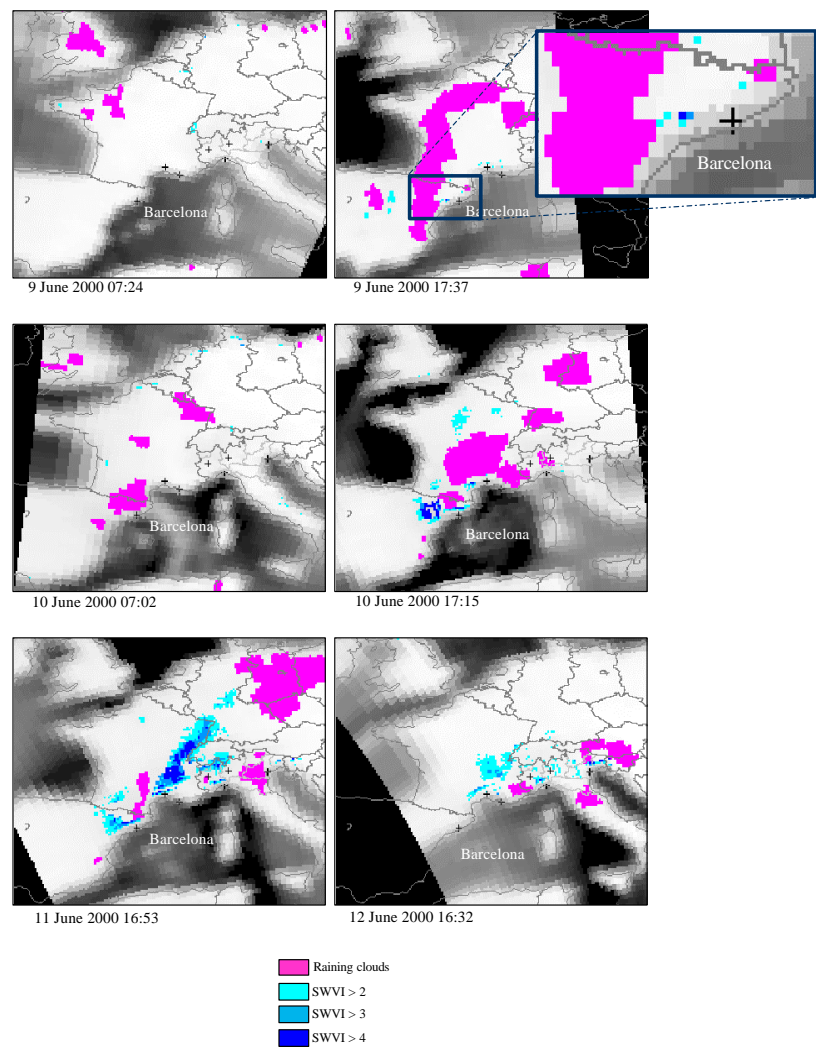

Fig. 3. Maps of $S W V I(x, y, t)$ for several days in June 2000. Different values of $S W V I(x, y, t)$ have been coloured in different shades of blue (i.e. higher $S W V I$ values are shown in the darkest blue) and overlayed on the corresponding AMSU images (channel $1,23.80 \mathrm{GHz}$ ) represented in grey tones (higher brightness temperatures are shown in brighter grey tones); only land pixels have been analyzed. The raining clouds are also shown (wherever they are present) in magenta (see text). In particular, for the image of 9 June 2000 at 17:37, a magnification of the area within the blue rectangle has been added.

\section{Implementation}

In order to apply the proposed approach to these flooding events, the first step was the selection and collection of all necessary AMSU imagery, taking into account the RAT approach prescriptions. For each flood event all the images acquired in the same months of event occurrences (but in different years) have been selected; furthermore, two distinct datasets were selected for each event, depending on the hour of pass. One dataset included all the imagery acquired between 5:00 and 7:00 GMT, while the other one included all the data collected between 15:00 and 18:00 GMT, respectively. Each of these two data-sets consists of about 150 images ( 30 per year, for 5 years) acquired in the years 1998-2003 excluding, for each dataset, the year which was perturbed by the flooding event to be studied. At the end of the processing phase, we have generated six different data-sets (two for each event). All the about 900 images were processed by means of AAPP software (ATOVS and AVHRR Processing Package),

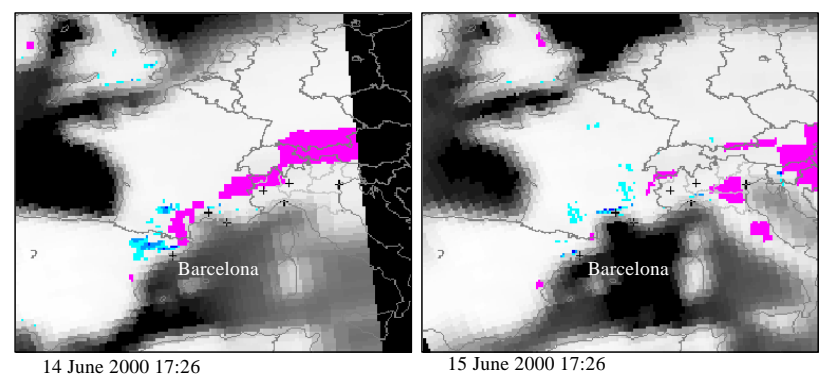

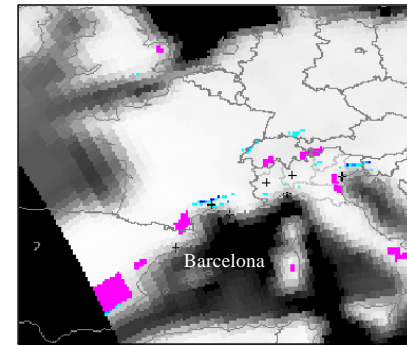

16 June 2000 17:04

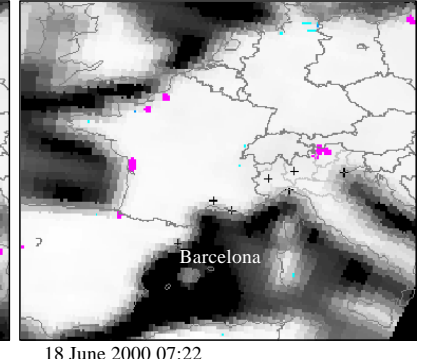

18 June 2000 07:22

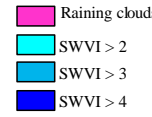

Fig. 3. Continued.

developed by EUMETSAT (Mèteo France document, 1999), co-located in the space domain (cell resolution $\cong 18 \mathrm{~km}$ ) with a specific developed tool and reprojected in a common geographic projection (Lambert Azimuthal Equal Area) over the Region of Interest (ROI). Subsequently, for both the above described homogeneous datasets and for each of the three selected study cases, the reference fields (time average $\mu_{S W I}(x, y)$ and standard deviation $\left.\sigma_{S W I}(x, y)\right)$ were generated, at pixel level, for the relevant ROI. As an example, Fig. 2 shows $\mu_{S W I}(x, y)$ (on the left) and $\sigma_{S W I}(x, y)$ (on the right) computed for the first dataset (acquisition time between 5:00 and 7:00 GMT) for the month of September. Note as the $S W I$ natural variability (represented by the $\sigma_{S W I}(x, y)$ field) is clearly greater over the coasts, where, because of the polar attitude of NOAA spacecrafts, AMSU FOVs include areas with different sea/land ratio each time. However, an anomalous $S W V I$ value still be detected in such an area as well, provided that the deviation of $S W I$ from its expected value (historically observed under similar observational and seasonal conditions in unperturbed periods) is higher than the observed variability.

Finally, by comparing each image of the sequence acquired during the considered flooding event with the relevant reference fields, the $S W V I(x, y, t)$ (Eq. 2) was computed and used to identify fluctuations of soil wetness in the spacetime domain. 


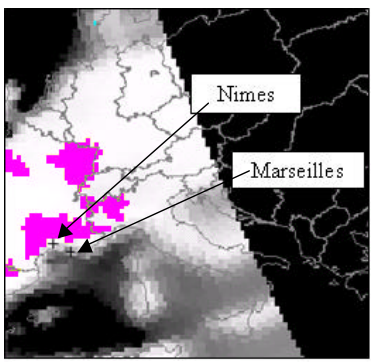

03 September 2002 17:14

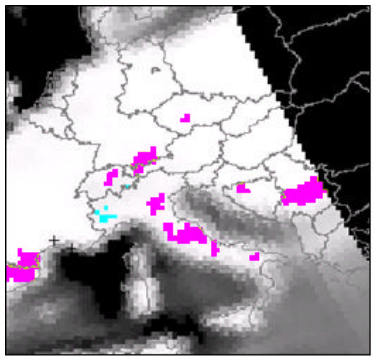

04 September 2002 16:49

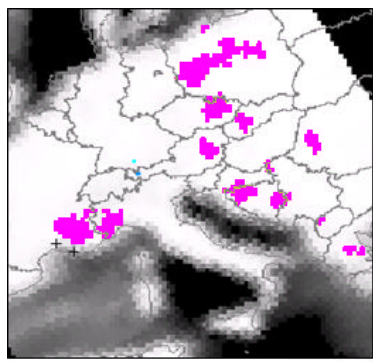

05 September 2002 16:04

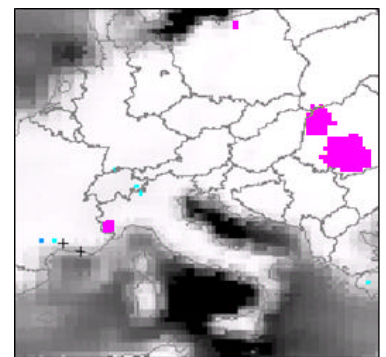

04 September 2002 06:13
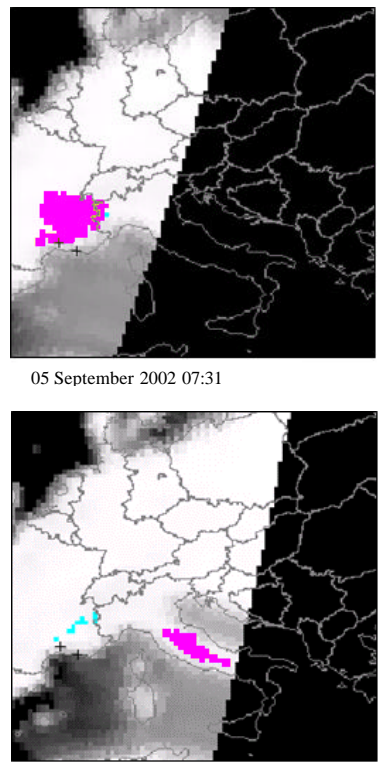

06 September 2002 07:08
05 September 2002 07:31

\section{$\square$ Raining cloud \\ $\square$ swVI $>2$ \\ SWVI $>4$}

Fig. 4. As Fig. 3 for September 2002.

\section{Results}

The SWVI maps generated for all the HYDROPTIMET study cases are presented in Figs. 3, 4 and 5. Generally, the areas hit by the flooding events have been analyzed before, during and after the selected events, in order to evaluate the reliability of the proposed index in following the space-time evolution of the flooding as well as in observing possible early signals which may possibly announce the impending flood.

\subsection{9-10 June 2000, Catalonia (Spain)}

Figure 3 reports the maps of $S W V I(x, y, t)$ generated for several days in June 2000 over the ROI; in the figures raining clouds (in magenta) are also shown (wherever they are present), identified by a screening test proposed by Grody et al. (2000) using AMSU data as well. The analysis of the $S W V I(x, y, t)$ maps shows the sudden response (in terms of soil wetness variations) of the soil to the precipitation fallen between 9th and 10th of June in Spain. Particularly interesting are the results obtained on the 9th of June at 17:37 GMT (see in Fig. 3 the magnification of the area within the blue

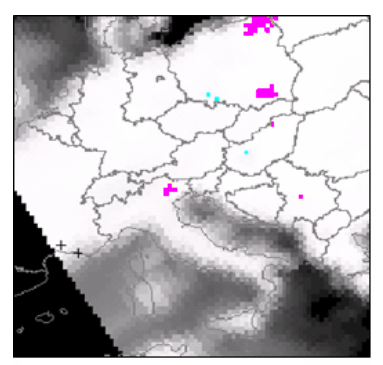

$$
06 \text { September } 2002 \text { 15:40 }
$$

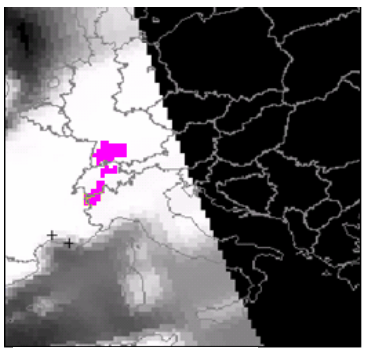

07 September 2002 16:57

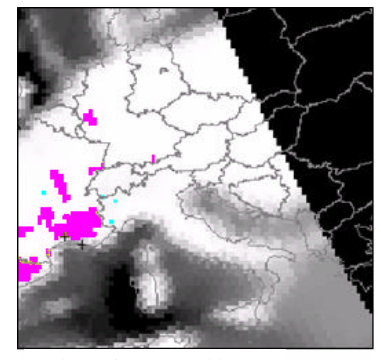

08 September 2002 16:33

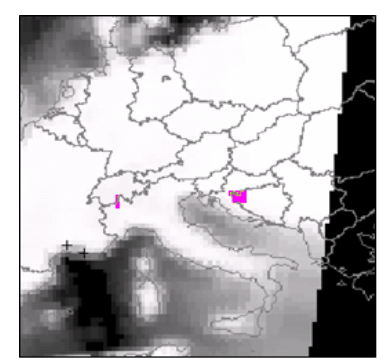

07 September 2002 06:45

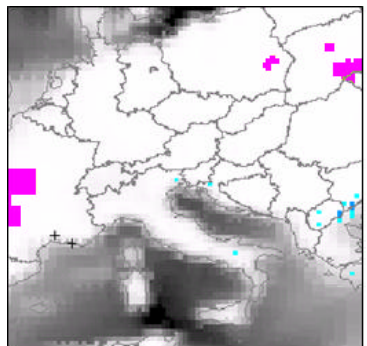

08 September 2002 06:16

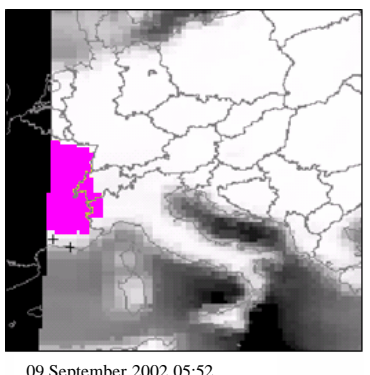

09 September 2002 05:52

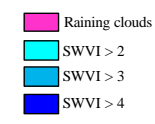

Fig. 4. Continued.

rectangle), where clear positive anomalies in soil wetness (with a maximum value $>4$ ) is observed near Barcelona, just over the area hit by the flash flood the day after. It could be viewed as an "early" sign of the wet conditions of the exposed soils which, as a consequence, were no longer capable to soak up further rainfall. In fact, in the map of 10th June it can be observed: i) an extended raining cloud is present on the area, suggesting the presence of a residual tail of precipitation which may mask the surface of the whole area, preventing a reliable and effective detection of anomalous soil wetness conditions (on the map derived at 07:02 GMT); ii) at 17:15 GMT, when the raining cloud moves towards France, a large $S W V I$ anomaly (both in size and intensity) is clearly visible, as a direct consequence of the precipitation fallen during the previous night. In the following days, the effect in Spain decreases (SWVI values are lower as well as the areas involved are smaller) but it is still active in France (with a plain persistence near the area around Nimes) and in Italy, immediately after the raining cloud passage (the event actually moved towards southern France and north-western Italy in those days). After 16 June, the situation returns to a normal state, without any anomalies over the whole investigated 


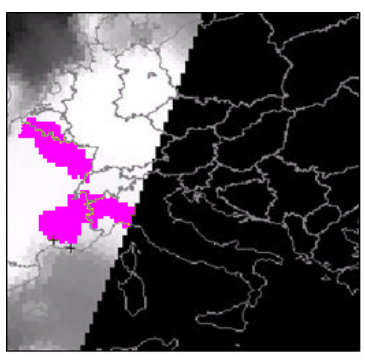

09 September 2002 07:38

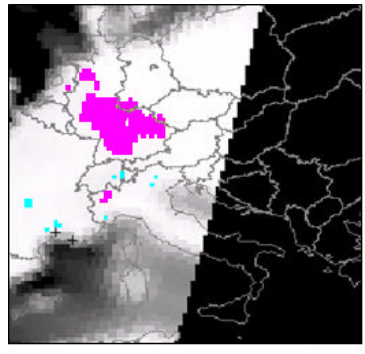

10 September 2002 07:14

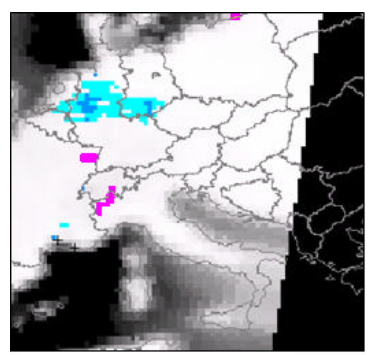

11 September 2002 06:50

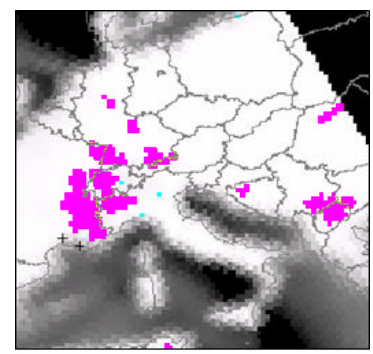

09 September 2002 16:10

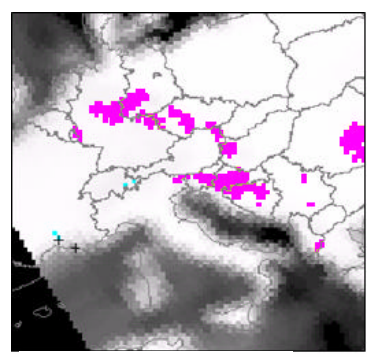

10 September 2002 15:46

12 September 2002 06:20
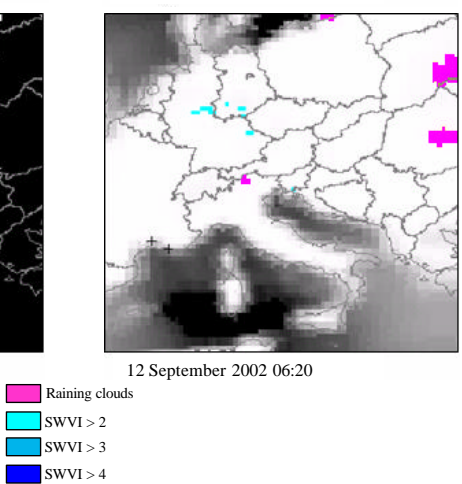

Fig. 4. Continued.

area, confirming the reliability and robustness of the indicator also in unperturbed conditions (i.e. low rate of false alarms).

\subsection{8-9 September 2002, Cévennes (France)}

The analysis of the SWVI maps (Fig. 4) shows the presence in the area which will be affected by the flood event, of pixels with anomalous values of $S W V I$ already before the beginning of the main meteorological event, in particular on the 4th and 6th of September. They might be caused by the light precipitation which occurred on the 3rd and 5th of September, confirmed also by the presence, on the maps shown in Fig. 4, of extended raining clouds over the area (see for instance the map of 3rd of September at 17:14 GMT and both the maps of 5th of September).

Afterwards, for more than $48 \mathrm{~h}$, from the afternoon of 6th of September to the evening of 8th of September, soils appear to be back to normal conditions. The maps of 8th and 9th of September clearly show the presence of heavy raining clouds over the area; as the clouds move, within the zone of Nimes, some $S W V I$ slight anomalies appear. In this case, the time persistence more than the spatial extent and the inten-
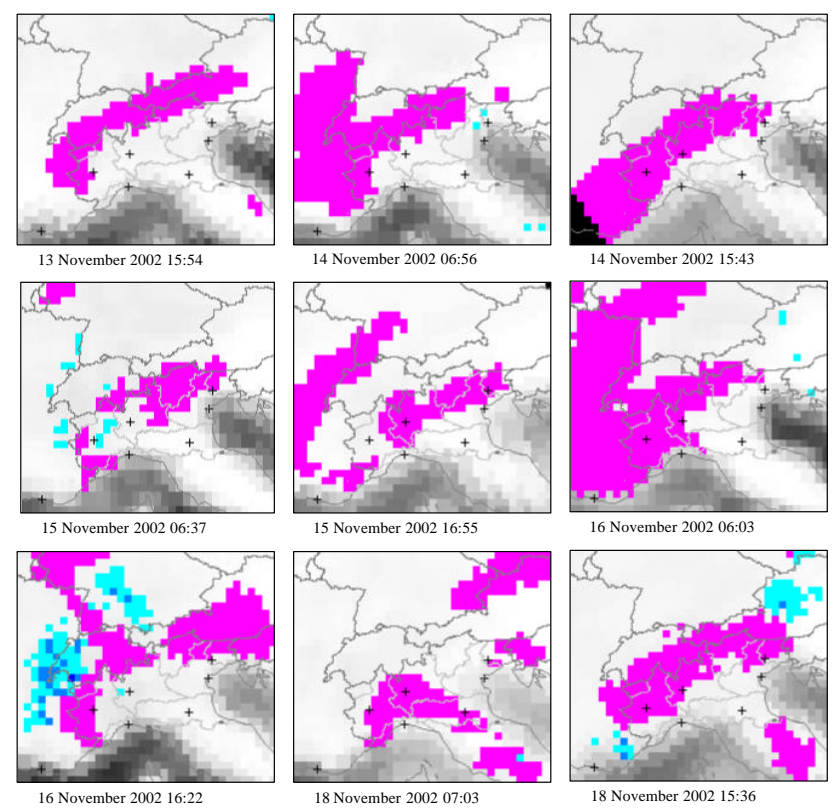

15 November 2002 16:55

16 November 2002 06:03
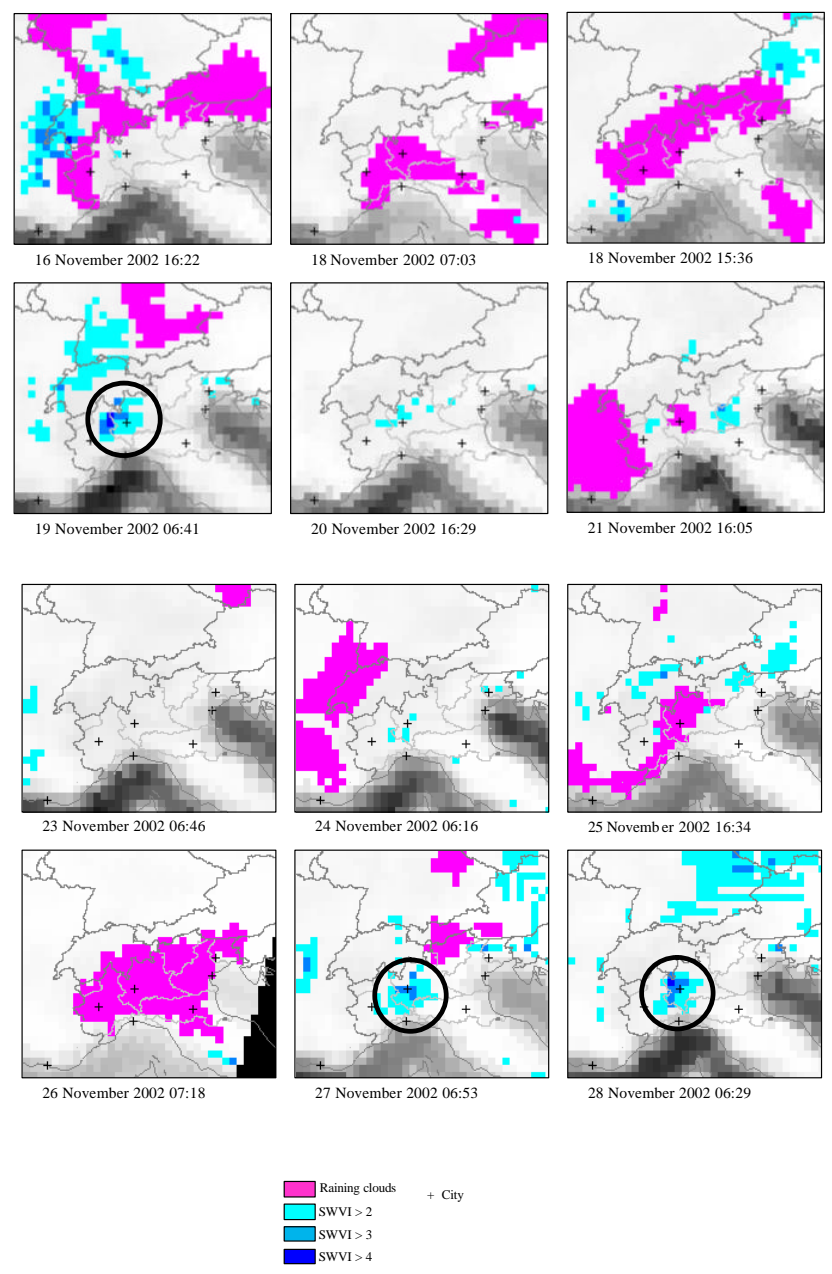

Fig. 5. As Fig. 3 for November 2002.

sity seem to suggest that this increase in SWVI may actually be related to the heavy rains fallen in a few hours. Looking at the figures, in fact, SWVI values between 2 and 3 were observed next to Nimes area for about $24 \mathrm{~h}$ (i.e. from 10th of September at 07:14GMT until 11th of September at 06:50GMT). Subsequently, these anomalies disappear and the whole scene seems to return to initial (i.e. unperturbed) conditions. 
Although also in this case slight anomalies were observed before the main event, their interpretation as pre-flooding warning signals is harder in this case, because they actually disappear in the maps of the following days, suggesting a quick return of soils to initial conditions. On the other hand, the prompt response of these soils, also to light rains (as the ones fallen on the 3rd and 5th of September), reveals that they are probably very sensitive to precipitation and less efficient to soak up the rain and consequently, more prone to be flooded. In fact, the persistent anomalies observed after the main meteorological event of 8-9 September were localized exactly within the same areas affected by the light, preceding rains. This circumstance, if confirmed by future studies, may open $S W V I$ to different application scenarios, as the support to the definition of flooding hazard maps.

\section{$6.3 \quad 14-18$ and 23-27 November 2002, Piedmont (Italy)}

In Fig. 5 the $S W V I$ maps generated for this event are presented. The analysis of the time series of such maps still reveals how such an index is capable to recognize the effects of precipitation in terms of soil wetness changes. These effects are clearly explained observing the maps at the end of the two meteorological events: higher and larger values of SWVI are, in fact, clearly observable on the image of 19th of November and on the maps of 27th and 28th of November, just at the end of the main precipitation events, outlining and enforcing the "double" nature of such an event. The return to normal conditions (i.e. unperturbed) is also well documented in this case, as confirmed by the absence of anomalous pixels in the relevant images. The obtained results seem to confirm as the "double" nature of this event might have emphasized the effects. Looking at the maps, in fact, after the 19th of November some slight $S W V I$ anomalies still remain present over the ROI (see for instance maps of 20th, 21st and 24th of November), confirming as over the region the initial conditions were perhaps never completely reached before the beginning of the second precipitation occurrence.

In conclusion, the results seem to confirm the reliability of the proposed technique for the identification of different amounts of soil wetness: SWVI was able to document the actual effects of meteorological events, in terms of spacetime evolution of soil wetness changes, for all the analysed HYDROPTIMET test cases. Moreover, the results obtained suggest the opportunity to assimilate such an index in the pre-operational phases of the modern flood warning systems, in order to improve their forecast capabilities and their reliability.

\section{Conclusions}

In this paper, a recently proposed AMSU-based Soil Wetness Variation Index ( $S W V I)$, aimed to improve soil wetness monitoring capabilities in the space-time domain and to possibly contribute to hydro-meteorological risk mitigation, has been implemented and tested on the three selected HYDROPTIMET test cases.

Results achieved seem to demonstrate the efficiency of the proposed indicator in detecting soil wetness variations in the space-time domain, also related to minor precipitation events. Furthermore, the proposed change detection scheme allowed us to overcome (or strongly reduce) site effects, like those connected to the surface roughness or vegetation cover or due to the presence of stable water bodies within the sensor FOV.

The suggested technique reveals its capability to monitor the time evolution of the flooding cycle, being able to follow all the "wet-to-dry" phases of the considered events. Moreover, the analysis carried out in this paper confirms the reliability of this method, as no "false positive" indications have been recorded during all the considered periods and over the study areas.

In particular, results obtained for the Spanish case in June 2000 show deviations from the "normal behavior" (in terms of soil wetness) of investigated soils a few days before the beginning of the main meteorological event which caused the flooding phase within the study area. Such a result suggests the possibility to employ the $S W V I$ as a further parameter to be used in the predicting chain devoted to the mitigation of hydrological risk. When intense precipitation are forecasted, in fact, the knowledge of soil wetness conditions could be used to better define the hazard scenarios and the alert state of the involved area. Moreover, thanks to the NOAA satellites constellation, the possibility of a SWVI updating every six hours, allows us a near-real-time monitoring of soil wetness, making it a useful tool also in the nowcasting phase. Furthermore, the supposed efficiency of SWVI to identify and map soils which, by composition, geology, location, etc. might be more prone to flood occurrence than others, deserves further investigation to be validated in order to assess the potential of such an indicator to the definition of flooding hazard maps.

Finally, because of the complete independence from the specific satellite platform, such a technique could be easily exported to the new generation of satellite microwave sensors, with improved performances, like the present AMSR-E aboard EOS-Aqua and the incoming MIRAS aboard the next ESA mission SMOS.

Acknowledgements. This work was carried out in collaboration with the Basilicata Region within the "HYDROPTIMET" project, in the framework of the "Interreg IIIB - Medocc" program.

Edited by: R. Romero

Reviewed by: V. Homar and D. Rabuffetti

\section{References}

Ahmed, N. U.: Estimating soil moisture from $6.6 \mathrm{GHz}$ dual polarizations, and/or satellite derived vegetation index. Int. J. Remot., 16(4), 687-708, 1995.

Basist, A., Grody, N., Peterson, T. C., and Williams, C. N.: Using the Special Sensor Microwave/Imager to Monitor Land Surface Temperatures, Wetness, and Snow Cover, J. Appl. Met., 37, 888911, 1998. 
Basist, A., Williams, C. Jr., Grody, N., Ross, T. F., Shen, S., Chang, A. T., Ferraro, R. R., and Menne, M. J.: Using the Special Sensor Microwave/Imager to Monitor Surface Wetness, J. Hydrol., 2, 297-308, 2001

CEOS (Committee on Earth Observation Satellites): Soil Moisture. Heart Observation Handbook (2003 Update): Earth observation by plans: measurements, 83, 2003.

Choudhury, B. J., Schmugge, T. J., Chang, A. and Newton, R. W.: Effects of Surface Roughness on the Microwave Emission from Soil, J. Geophys. Res., 84(C9), 5699-5706, 1979.

Choudhury, B. J. and Golus R.: Estimating soil wetness using satellite data, Int. J. Remot., 9(7), 1251-1257, 1988.

Eagleman, J. R. and Lin, W. C.: Remote Sensing of Soil Moisture by a 21-cm Passive Radiometer, J. Geophys. Res., 81, 36603666, 1976.

Entekhabi, D., Nakamura, H., and Njoku, E. G.: Solving the Inverse Problem for Soil Moisture and Temperature Profiles by Sequential Assimilation of Multifrequency Remotely Sensed Observations, IEEE Trans. Geosci. Rem. Sens., 32(2), 438-448, 1994.

Ferraro, R. R., Grody, N. C., and Kogut, J. A.: Classification of Geophysical Parameters Using passive Microwave satellite measurements, IEEE Trans. Geosci. Rem. Sens., Vol. GE-24(6): 1008-1013, 1986.

Ferraro, R. R., Weng, F., Grody, N. C. and Basist, A.: An eight year (1987-1994) climatology of rainfall, clouds, water vapour, snow cover, and sea-ice derived from SSM/I measurements, Bull. Of Amer. Meteor. Soc., 77, 891-905, 1996.

Galantowicz, J. F., Entekhabi, D., and Njoku, E. G.: Tests of Sequential Data Assimilation for Retrieving Profile Soil Moisture and Temperature from Observed L-Band Radiobrightness, IEEE Trans. Geosci. Remote Sens., 37(4), 1860-1870, 1999.

Goodrum, G., Kidwell, K. B, and Winston, W.: NOAA KLM user's guide. NOAA, NOAA-NESDIS/NCDC, Suitland, Maryland, USA, 1997.

Grody, N. C., Weng, F., and Ferraro, R. R.: Application of AMSU for hydrological parameters, in: Microwave radiomemetry and remote sensing of the earth's surface and atmosphere, edited by: Pampaloni, P. and Paloscia, S., VSP, The Netherlands, 339-352, 2000.

Hollinger, J. R., Lo, B., Poe, G., Savane, R., and Pierce, J.: Special Sensor Microwave user's guide. Naval Res. Lab. Tech. Rep., Washington, DC, 119, 1997.

Jackson, T. J., Schmugge, T. J., Nicks, A. D., Coleman, G. A., and Engman, E. T.: Soil Moisture Updating and Microwave Remote Sensing for Hydrological Simulation, Hydrological Sciences Bulletin, 26(3), 305-319, 1981.

Jackson, T. J. and Schmugge, T. J.: Passive Microwave Remote Sensing System for Soil Moisture: Some Supporting Research, IEEE Trans. Geosci. Rem. Sens., 27, 225-235, 1989.

Jackson, T. J. and Schmugge, T. J.: Vegetation effects on the microwave emission from soils, Remot. Sen. E., 36, 203-212, 1991.

Jackson, T. J.: III. Measuring Surface Soil Moisture Using Passive Microwave Remote Sensing. Hydrol. Proc., 7, 139-152, 1993.

Jackson, T. J.: Soil Moisture estimation using special satellite microwave/imager satellite data over a grassland region, Water Res. R., 33(6), 1475-1484, 1997.

Jackson, T. J., Hsu, A. Y., and O'Neill, P. E.: Surface Soil Moisture Retrieval and Mapping Using High Frequency Microwave Satellite Observations in the Southern Great Plains, J. Hydromete., 3, 688-699, 2002.

Kim, G., and Barros, A. P.: Space-time characterization of soil moisture from passive microwave remotely sensed imagery and ancillary data, Remot. Sen. E., 81, 393-403, 2002.

Lacava, T.: Sviluppo di tecniche satellitari a microonde per il monitoraggio del rischio idrometeorologico, $\mathrm{Ph}$. D. Thesis (available at University of Basilicata, Potenza, Italy), 2004.

Lacava, T, Di Leo, E. V., Pergola, N., Romano, F., Sannazzaro F., and Tramutoli, V.: Analysis Of Multi-Temporal Satellite Records For Extreme Flooding Events Monitoring, Proceedings of the 5th EGS Plinius Conference held at Ajaccio, Corsica, France, October 2003, edited by: Testud, J., Mugnai, A., and Santucci, J. F., 231-237, 2004.

Lacava, T., Cuomo, V., Di Leo, E. V., Pergola, N., Romano, F., and Tramutoli, V.: Improving soil wetness variations monitoring from passive microwave satellite data: the case of April 2000 Hungary flood, Remot. Sen. E., accepted, 2005.

Lakshmi, V., Wood, E. F., and Choudhury, B. J.: Evaluation of Special Sensor Microwave/Imager Satellite Data for Regional Soil Moisture Estimation over the Red River Basin, J. Appl. Met., 36, 1309-1328, 1997.

Mètèo France documentation: General specifications for the AAPP preprocessing package related to NOAA polar orbiting weather satellites. Software description, 1999.

Njoku, E. G. and Entekhabi, D.: Passive microwave remote sensing of soil moisture, J. Hydrol., 184, 101-129, 1996.

Njoku, E. G. and Li, L.: Retrieval of land surface parameters using passive microwave measurements at $6-18 \mathrm{GHz}$, IEEE Trans. Geosci. Rem. Sens., 37(1), 79-93, 1999.

Paloscia, S., Pampaloni, P., Chiarantini L., Coppo P., Gagliani S., and Luzi, G.: Multifrequency passive remote sensing of soil moisture and roughness, Int. J. Remot., 14(3), 467-483, 1993.

Paloscia, S., Macelloni, G., Santi, E., and Koite, T.: A Multifrequency Algorithm for the Retrieval of Soil Moisture on a Large Scale Using Microwave Data from SMMR and SSM/I Satellites, IEEE Trans. Geosci. Rem. Sens., 39(8), 1655-1661, 2001.

Prigent, C., Rossow, W. B., and Matthews, E.: Microwave land surface emissivity estimated from SSM/I, J. Geophys. Res., 102(21), 867-890, 1997.

Pultz, T. J, Leconte, R., Laurent, L. St., and Peters, I.: Flood mapping with airborne SAR imagery: case of the 1987 St. John River flood, Canadian Water Resources Journal, 16, 2, 173-189, 1991.

Pultz, T. J., Crevier, Y. Brown, R. J., and Boisvert, J.: Monitoring of local environmental conditions with SIR-C/X-SAR, Remot. Sen. E., 59, 4, 248-255, 1997.

Ruf, C. S. and Zhang, H.: Performance evaluation of single and multichannel microwave radiometers for soil moisture retrieval, Remot. Sen. E., 75, 86-99, 2001.

Schmugge, T. J., Jackson, T. J., and McKim, H. L.: Survey of Methods for Soil Moisture Determination, Water Res. R., 16(6), 961979, 1980.

Schmugge, T. J.: Applications of passive microwave observations of surface soil moisture, J. Hydrol., 212-213, 188-197, 1998.

Schmugge, T. J., Kustas, W. P, Ritchie, J. C., Jackson, T. J., and Rango, A.: Remote Sensing in hydrology, Adv. Water R., 25, 1367-1385, 2002.

Scofield, R. A. and Achutuni, R.: The satellite forecasting funnel approach for predicting flash floods, Remote Sensing Reviews, 14, 251-282, 1996.

Songyan, G., Huilin, G., Yuanjing, Bolin Z., Wenjian, Z., Hong, Q., and Maonong, R.: Flood detection and Monitoring by using of AMSU-A microwave data, Proceedings of the 20th International ATOVS Study Conference, Budapest, Hungary, 20-26 September 2000,2000 . 
Teng, W. L., Wang, J. R., and Doraiewamy, P. C.: Relationship between satellite microwave radiometric data, antecedent precipitation index, and regional soil moisture, Int. J. Remot., 14(13), 2483-2500, 1993.

Tramutoli, V.: Robust AVHRR Techniques (RAT) for Environmental Monitoring theory and applications, in: Earth Surface Remote Sensing II, edited by: Cecchi, G. and Zilioli, E., SPIE 3496, 101113, 1998.

Walker, J. P. and Houser, P. R.: Requirements of a global nearsurface soil moisture satellite mission: accuracy, repeat time, and spatial resolution, Adv. Water. R., 27, 785-801, 2004.

Wang, J. R., O’Neill, P. E., Jackson, T. J., and Engman, E. T.: Multifrequency Measurements of the effects of Soil Moisture, Soil Texture, and Surface Roughness, IEEE Trans. Geosci. Rem. Sens., GE-21 Eq. (1), 44-51, 1983.
Wang, J. R.: Effect of Vegetation on Soil Moisture Sensing Observed from Orbiting Microwave Radiometers, Remot. Sen. E., 17, 141-151, 1985.

Wigneron, J. P., Schmugge, T. J., Chanzy, A., Calvet, J. C., and Kerr, Y.: Use of passive microwave remote sensing to monitor soil moisture, Agronomie, 18, 27-43, 1998.

Wigneron, J. P., Calvet, J. C., Pellarin, T., Van de Griend, A. A., Berger, M., and Ferrazzoli, P.: Retrieving near-surface soil moisture from microwave radiometric observations: current status and future plans, Remot. Sen. E., 85, 489-506, 2003.

William, C., Basist, A., Peterson, T. C., and Grody, N.: Calibration and validation of land surface temperature anomalies derived from SSM/I. Bull, Americ. Meteor. Soc., 81, 2141-2156, 2000. 